\title{
Artificial diets for the rice grasshopper, Oxya yezoensis Shiraki (Orthoptera: Catantopidae)
}

\author{
Yasuhiko KonNo* \\ Graduate School of Agricultural Science, Tohoku University; Sendai, Miyagi 981-8555, Japan
}

(Received 24 February 2004; Accepted 23 June 2004)

\begin{abstract}
Newly-hatched nymphs of the rice grasshopper, Oxya yezoensis Shiraki (Orthoptera: Catantopidae) were reared on artificial diets. The artificial diets consisted of dry leaf powder from one of three Gramineae plants, dried brewers' yeast, milk casein, wheat germ powder, sucrose, $\beta$-sitosterol, Beck's salt mixture, ascorbic acid, vitamin B mixture, L-cysteine, sorbic acid, propionic acid, agar, and water. There were no significant differences in the nymphal period, percentage of adult emergence, adult weights, and the number of egg-pods laid per female between hoppers reared on the artificial diet and those reared on fresh rice seedlings. The present study is the first report on the successful rearing of the Catantopidae species on an artificial diet.
\end{abstract}

Key words: Oxya yezoensis; rice grasshopper; artificial diet

\section{INTRODUCTION}

The rice grasshopper, Oxya yezoensis Shiraki is one of the most abundant pests in paddy fields in Japan. Surveys made in 1989-1992 showed that this grasshopper occurred in at least 45 out of 71 localities between $31^{\circ} \mathrm{N}$ and $43^{\circ} \mathrm{N}$ (Ando and Yamashiro, 1993). Recently, O. yezoensis has been found in very large numbers and it causes severe damage to paddy fields in northeastern Honshu (Ando, 1993; Ishiguro, 1994; Kidokoro and Kondo, 1998). Many authors have attempted to elucidate the cause of the outbreaks and have explained that $O$. yezoensis has acquired resistance to organophosphorus, carbamate, and pyrethroid insecticides, which had been used intensively in paddy fields (Ito and Ichikawa, 1995; Konno, 1999; Ishioka and Kimura, 2001).

There have been several reports of successful rearing of Orthoptera on an artificial diet. Dadd (1960) developed an artificial diet for the migratory locust, Locusta migratoria. The diet has been used for the nutritional and physiological studies of Schistocerca gregaria and S. americana (Simpson and Abisgold, 1985; Bernays and Chapman, 1998; Behmer and Elias, 1999; Chapman, 2002; Simpson et al., 2002). On the other hand, rearing of $O$. yezoensis in the laboratory has been practiced using fresh leaves of Gramineae plants (Ando and Yamashiro, 1993; Konno, 2001), and there has been no report on an artificial diet. In this paper, therefore, the author reports the rearing results of O. yezoensis on artificial diets.

\section{MATERIALS AND METHODS}

Insects. Adults $O$. yezoensis were collected in paddy fields in Sendai, Miyagi Prefecture, Japan in September 2001. A laboratory culture originating from these adults has been maintained under $16 \mathrm{~L}-8 \mathrm{D}$ at $23 \pm 1^{\circ} \mathrm{C}$. Approximately ten adults $\left(5 \circ 50^{\star}\right)$ were reared with rice plant seedlings (Oryza sativa L.) in an insect cage $(34 \times 26 \times$ $34 \mathrm{~cm}$, Shigemi Standard Co. Ltd., Tokyo) made of plastic frames and nylon gauze with detachable veneer floors for cleaning. A plastic cup $(15 \times 8 \times$ $5 \mathrm{~cm}$ ) was filled with sand and was put in the cage for egg-laying. The sand was dried and sterilized at $150^{\circ} \mathrm{C}$ before use and was moistened with distilled water. The egg-pods deposited in the sand were collected and kept in petri dishes with the moistened sand. The egg-pods in the petri dishes were

*E-mail: konnoy@bios.tohoku.ac.jp

DOI: 10.1303/aez.2004.631 
then stored at $4{ }^{\circ} \mathrm{C}$ for two months. After cold storage, nymphs emerged normally when the $4^{\circ} \mathrm{C}$ treated egg-pods were incubated for about two weeks at $23 \pm 1^{\circ} \mathrm{C}$.

Composition and preparation of artificial diets. The compositions of three kinds of artificial diet are shown in Table 1. All ingredients except propionic acid, agar and water were mixed well in a $100-\mathrm{ml}$ glass beaker. A boiled agar solution $(1 \mathrm{~g} / 60 \mathrm{ml})$ was then added to the blended ingredients in a glass beaker. After cooling to below ca.

Table 1. Composition of artificial diets for the rice grasshopper, Oxya yezoensis

\begin{tabular}{llll}
\hline \multicolumn{1}{c}{ Ingredients } & Diet A & Diet B & Diet C \\
\hline Leaf powder of Oryza sativa & $5 \mathrm{~g}$ & - & - \\
Leaf powder of Setaria viridis & - & $5 \mathrm{~g}$ & - \\
Leaf powder of Miscanthus sinensis & - & - & $5 \mathrm{~g}$ \\
Dried brewers' yeast (Ebios ${ }^{\circledR}$ ) & $1 \mathrm{~g}$ & $1 \mathrm{~g}$ & $1 \mathrm{~g}$ \\
Milk casein & $1 \mathrm{~g}$ & $1 \mathrm{~g}$ & $1 \mathrm{~g}$ \\
Wheat germ powder $_{\text {Sucrose }}$ & $5 \mathrm{~g}$ & $5 \mathrm{~g}$ & $5 \mathrm{~g}$ \\
$\beta$-sitosterol & $0.5 \mathrm{~g}$ & $0.5 \mathrm{~g}$ & $0.5 \mathrm{~g}$ \\
Beck's salts mixture & $0.03 \mathrm{~g}$ & $0.03 \mathrm{~g}$ & $0.03 \mathrm{~g}$ \\
Ascorbic acid & $0.2 \mathrm{~g}$ & $0.2 \mathrm{~g}$ & $0.2 \mathrm{~g}$ \\
Vitamin B mixture & $0.2 \mathrm{~g}$ & $0.2 \mathrm{~g}$ & $0.2 \mathrm{~g}$ \\
L-cysteine & $0.1 \mathrm{~g}$ & $0.1 \mathrm{~g}$ & $0.1 \mathrm{~g}$ \\
Sorbic acid & $0.02 \mathrm{~g}$ & $0.02 \mathrm{~g}$ & $0.02 \mathrm{~g}$ \\
Propionic acid & $0.02 \mathrm{~g}$ & $0.02 \mathrm{~g}$ & $0.02 \mathrm{~g}$ \\
Agar & $0.2 \mathrm{ml}$ & $0.2 \mathrm{ml}$ & $0.2 \mathrm{ml}$ \\
Water & $1 \mathrm{~g}$ & $1 \mathrm{~g}$ & $1 \mathrm{~g}$ \\
\end{tabular}

${ }^{\text {a }}$ Beck et al. (1968).

${ }^{\mathrm{b}}$ Ishii and Urushibata (1954). $60^{\circ} \mathrm{C}$, propionic acid was added and gently mixed for a few seconds. The diets thus made up were stored at $4^{\circ} \mathrm{C}$ in a refrigerator until use. Three kinds of leaf powder of Gramineae plants were prepared as follows. Fresh leaves were heated at $80^{\circ} \mathrm{C}$ in an incubator for $4 \mathrm{~h}$. After cooling, the dried leaves were crushed to a powder using a juice mixer (Matsushita Electric Industrial Co., Ltd., Osaka). The dried leaf powders were stored at $4{ }^{\circ} \mathrm{C}$ in a refrigerator until use.

General rearing procedure. A filter paper $(13 \mathrm{~cm}$-diam.) was placed on the bottom of a plastic container (13 cm-diam., $7 \mathrm{~cm}$-depth) and moistened with distilled water. Twenty new hatchlings were then placed in the plastic container with a $3 \mathrm{~g}$ lump of the artificial diet. The diet was set on an absorbent cotton, which was placed on the bottom of a plastic dish ( $3 \mathrm{~cm}$-diam.). The absorbent cotton was moistened with distilled water to prevent the diet from desiccatings. The plastic container was then covered with a lid with a Saran ${ }^{\circledR}$ net window $(2 \mathrm{~cm}$-diam.) and kept under 16L-8D at $23 \pm 1{ }^{\circ} \mathrm{C}$. When the hoppers reached the fourth instar, they were transferred to the insect cage with a $10 \mathrm{~g}$ lump of the artificial diet. The diet was set on moistened absorbent cotton which was placed on the bottom of a petri dish ( $9 \mathrm{~cm}$-diam.). (Fig. 1). After adult emergence, a plastic cup $(15 \times 8 \times 5 \mathrm{~cm})$ filled with moistened sand was put in the cage for egg-laying. During the rearing period from hatchling to adult, the artificial diet was replenished every three days.

Characteristics measured. The characteristics

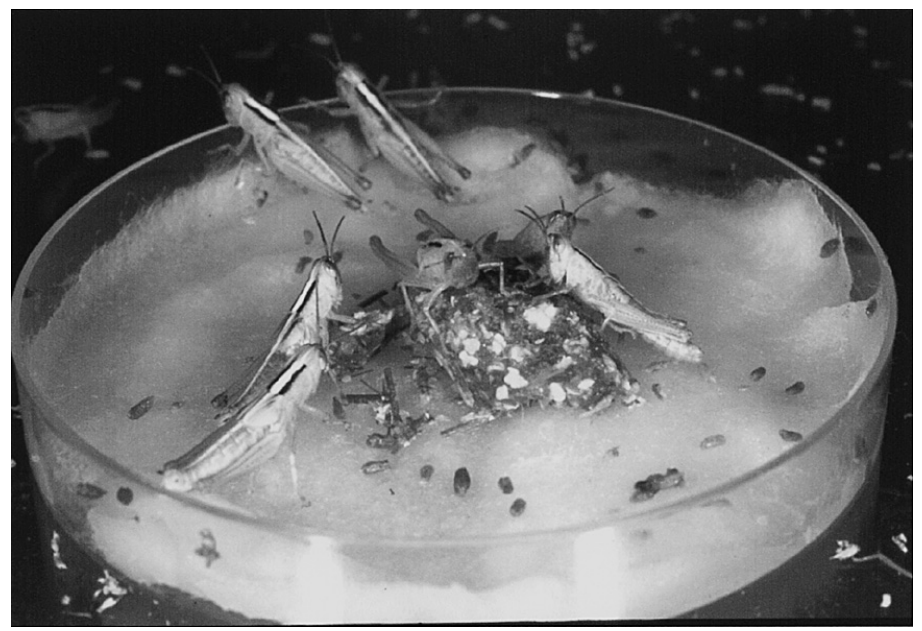

Fig. 1. Rearing of fourth instar hoppers of Oxya yezoensis on the artificial diet (Diet A). The artificial diet was set on moistened absorbent cotton which was placed on the bottom of a petri dish $(9 \mathrm{~cm}$-diam.). 
Table 2. Comparison of characters of the rice grasshopper, Oxya yezoensis reared on three artificial diets and fresh rice seedlings

\begin{tabular}{|c|c|c|c|c|c|c|c|}
\hline & \multirow{2}{*}{$\begin{array}{l}\text { No. eggs } \\
\text { used }\end{array}$} & \multicolumn{2}{|c|}{ Nymphal period (days) $^{\mathrm{a}}$} & \multirow{2}{*}{$\begin{array}{l}\% \text { of adult } \\
\text { emergence }\end{array}$} & \multicolumn{2}{|c|}{ Adult weight $(\mathrm{mg})^{\mathrm{a}}$} & \multirow{2}{*}{$\begin{array}{l}\text { No. egg cases } \\
\text { laid per female }\end{array}$} \\
\hline & & ot & o & & ot & $q$ & \\
\hline Diet A & 120 & $76.8 \pm 1.58 \mathrm{a}$ & $84.4 \pm 2.62 \mathrm{a}$ & 45.0 (26ð 289$)$ & $319.3 \pm 11.5 \mathrm{a}$ & $529.5 \pm 32.7 \mathrm{a}$ & $2.52 \pm 0.42 \mathrm{a}$ \\
\hline Diet B & 120 & $78.2 \pm 2.21 \mathrm{a}$ & $84.6 \pm 2.53 \mathrm{a}$ & 43.3 (27ð25 $)$ & $317.3 \pm 14.2 \mathrm{a}$ & $520.2 \pm 31.8 \mathrm{a}$ & $2.48 \pm 0.63 \mathrm{a}$ \\
\hline Diet C & 120 & $77.6 \pm 1.96 \mathrm{a}$ & $83.3 \pm 2.13 \mathrm{a}$ & $44.2(28 ð 25 q)$ & $316.8 \pm 17.3 \mathrm{a}$ & $517.5 \pm 33.5 \mathrm{a}$ & $2.47 \pm 0.32 \mathrm{a}$ \\
\hline $\begin{array}{l}\text { Fresh rice } \\
\text { seedlings }\end{array}$ & 120 & $77.8 \pm 1.28 \mathrm{a}$ & $82.2 \pm 1.46 \mathrm{a}$ & $46.7(30 \lesssim 26 \%)$ & $318.0 \pm 29.4 \mathrm{a}$ & $521.9 \pm 32.8 \mathrm{a}$ & $2.58 \pm 0.95 \mathrm{a}$ \\
\hline
\end{tabular}

${ }^{a}$ Values stand for means \pm SE. Values followed by the same letters in the same column are not significantly different at $p>0.05$ by Tukey-Kramer's test.

examined were the nymphal period, percentage of adult emergence, adult weight, and the number of egg-pods laid per female. In order to evaluate the quality of the artificial diet, the characteristics were compared with those of the control hoppers which were fed on a sufficient amount of fresh rice seedlings. The average height of the rice seedlings was ca. $30 \mathrm{~cm}$.

\section{RESULTS AND DISCUSSION}

Table 2 shows the development of the hatchlings reared on the three kinds of artificial diets and the rice seedlings. There were no significant difference in the nymphal period, adult weight, and the fecundity between the hoppers reared on the artificial diets and those on fresh rice seedlings ( $p>0.05$, Tukey-Kramer's test). In addition, there was no significant difference in the percentage of adult emergence between the hoppers reared on the artificial diets and those on fresh rice seedlings $\left(\chi^{2}=0.3, p>0.05, \mathrm{df}=3\right)$. These results indicate that the artificial diets are comparable to the rice seedlings in nutritional value for $O$. yezoensis. The present study is the first report on the successful rearing of the Catantopidae species on the artificial diet.

In the present study, three kinds of dry leaf powder were tested, i.e., O. sativa L. (Diet A), Setaria viridis Beauv. (Diet B) and Miscanthus sinensis Andress. (Diet C). As shown in Table 2, no significant difference was observed on the development of nymphs among the three diets. Because $S$. viridis and $M$. sinensis are common weeds in Japan, these weeds will be valuable substitutes when $O$. sativa is unavailable.
In phytophagous Orthoptera, artificial diets have been studied in Acrididae. Dadd (1960) developed an artificial diet for the migratory locust, Locusta migratoria, and the diet was used for the nutritional studies of the grasshoppers such as Schistocerca americana (Bernays and Chapman, 1998; Behmer and Elias, 1999; Chapman, 2002), Schistocerca gregaria (Simpson et al., 2002) and Romalea guttata (Jones et al., 1987, 1989). The diet developed by Dadd (1960) has no dry leaf powder, wheat germ, or other crude plant materials, and it consisted of casein, bacteriological peptone, egg albumen, sucrose, white dextrin, cellulose powder, linoleic acid, cholesterol, salt mixture, ascorbic acid, choline chloride, and vitamin B mixture. Because the artificial diet is chemically defined, the diet has been sufficiently complete to permit effective biochemical investigation of Acrididae's specific nutritional requirements.

In this study, the artificial diet for O. yezoensis contained the leaf powder of three different Gramineae plants. In general, chemically defined diet without plant materials have not proved very successful for the continuous rearing of a laboratory culture of any phytophagous species, because of suboptimal growth, a loss of viability, and an attenuation of fecundity over the span of several generations (Stanley et al., 1968). In fact, the absence of the dry leaf powder of Gramineae plants from the diet described in this study has resulted in nymphs of $O$. yezoensis that showed little stimulation to feed on the diet and no adults were obtained (Konno, unpublished data). Therefore, it was considered that one of the roles of the dry leaf powder is a feeding stimulant.

In conclusion, the artificial diets in the present 
study are sufficient for rearing $O$. yezoensis and no disadvantages were observed even in the second generation. The artificial diets are expected to be used for nutritional and physiological studies in $O$. yezoensis.

\section{REFERENCES}

Ando, Y. (1993) Outbreaks and ecology of rice grasshoppers. Plant Protect. 47: 311-319 (in Japanese).

Ando, Y. and C. Yamashiro (1993) Outbreaks and delayed hatching after hibernation in the rice grasshopper, Oxya yezoensis Shiraki (Orthopter: Catantopidae). Appl. Entomol. Zool. 28: 217-225.

Beck, S. D., G. M. Chippendale and D. E. Swinton (1968) Nutrition of the European corn borer, Ostrinia nubilalis. VI. A larval rearing medium without crude plant fractions. Ann. Entomol. Soc. Am. 61: 459-462.

Behmer, S. T. and D. O. Elias (1999) Phyosterol structure and its impact on feeding behaviour in the generalist grasshopper Schistocerca americana. Physiol. Entomol. 24: $18-27$.

Bernays, E. A. and R. F. Chapman (1998) Phenotypic plasticity in numbers of antennal chemoreceptors in a grasshopper: effects of food. J. Comp. Physiol. A 183: 69-76.

Chapman, R. F. (2002) Development of phenotypic differences in sensillum populations on the antennae of a grasshopper, Schistocerca americana. J. Morph. 254: 186-194.

Dadd, R. H. (1960) The nutritional requirements of locusts I. development of synthetic diets. J. Insect Physiol. 4: 319-347.

Ishiguro, K. (1994) Control threshold of the rice grasshopper Oxya yezoensis Shiraki on paddy rice. Bull. Yamagata Agric. Exp. Stn. 28: 57-68 (in Japanese).

Ishii, S. and H. Urushibata (1954) On fat soluble and water soluble growth factors required by the rice stem borer, Chilo simplex Butler. Bull. Natl. Inst. Agri. Sci. C4: 109-133.

Ishioka, M. and T. Kimura (2001) Insecticide susceptibility of the rice grasshopper, Oxya yezoensis Shiraki, in Aomori Prefecture. Ann. Rept. Plant Prot. North Japan 52: 132-134 (in Japanese).

Ito, K. and K. Ichikawa (1995) Pesticidal activity of seneral chemicals to the rice grasshopper, Oxya japonica, in Aichi Prefecture. Res. Bull. Aichi Agri. Res. Ctr. 27: 101-104 (in Japanese).

Jones, C. G., W. Douglas, J. S. Compton, P. J. Silk and M. S. Blum (1989) Reduction in diet breadth results in sequestration of plant chemicals and increases efficacy of chemical defense in a generalist grasshopper. J. Chem. Ecol. 15: 1811-1822.

Jones, C. G., T. A. Hess, D. W. Whitman, P. J. Silk and M. S. Blum (1987) Effects of diet breadth on autogenous chemical defense of a generalist grasshopper. J. Chem. Ecol. 13: 283-297.

Kidokoro, T. and Y. Kondo (1998) Farmer's awareness of the occurrence and abundance of the rice grasshopper in Tohoku district. Ann. Rept. Plant Prot. North Japan 49: 109-112 (in Japanese).

Konno, Y. (1999) Insecticide susceptibility of the rice grasshopper, Oxya yezoensis (Orthoptera: Catantopidae). Ann. Rept. Plant Prot. North Japan 50: 145-146 (in Japanese).

Konno, Y. (2001) Genetic factor affecting adult color polymorphism in the rice grasshopper, Oxya yezoensis (Orthoptera: Catantopidae). Jpn. J. Appl. Entomol. Zool. 45: 15-17 (in Japanese with English summary).

Simpson, S. J. and J. D. Abisgold (1985) Compensation by locusts for changes in dietary nutrients: behavioural mechanisms. Physiol. Entomol. 10: 443-452.

Simpson, S. J., D. Raubenheimer, S. T. Behmer, A. Whitworth and G. A. Wright (2002) A comparison of nutritional regulation in solitarious- and gregarious-phase nymphs of the desert locust Schistocerca gregaria. J. Exp. Biol. 205: 121-129.

Stanley, D. B., G. M. Chippendale and D. E. Swinton (1968) Nutrition of the European corn borer, Ostrinia nubilalis. VI. A larval rearing medium without crude plant fractions. Ann. Entomol. Soc. Am. 61: 459-462. 